\title{
Dihydroxyacetone as an Intermediate during the Metabolism of Glycerol and Glyceraldehyde in Leukocytes from Rat
}

\author{
V. ESMAN N
}

Department of Medicine, Marselisborg Hospital, Aarhus, Denmark

\begin{abstract}
The fate of ${ }^{14} \mathrm{C}$-labelled glycerol and glyceraldehyde has been followed in incubated leukocytes. When the position of the carbon atom is numbered from the reactive group, ${ }^{14} \mathrm{C}$ of $\mathrm{D}$ - and $\mathrm{L}_{-}-\left[3 \cdot{ }^{14} \mathrm{C}\right]-$ glyceraldehyde was randomized to C-1 of lactate suggesting dihydroxyacetone as an intermediate. Glyceric acids from $L_{-}$and $\mathrm{D}-\left[3{ }^{14} \mathrm{C}\right]$ glyceraldehyde were not randomized indicating that $D$ - and $I_{t}$-glyceraldehyde are not interconvertible over glycerol in leukocytes.

Lactate from $\left[1,3 \cdot{ }^{14} \mathrm{C}\right]$ - or $\left[2 \cdot{ }^{14} \mathrm{C}\right]$-glycerol was not randomized, whereas $\left[1 .{ }^{14} \mathrm{C}\right]$ - and $\left[3 \cdot{ }^{14} \mathrm{C}\right]-$ glycerol gave lactates with $60-80 \%$ of the activity in $\mathrm{C}-3$ and $20-30 \%$ in $\mathrm{C}-1$, which is explainable only by assuming a direct oxidation of glycerol at C-2 and subsequent isotopic dilution. The latter two compounds were used in high concentrations, which may have changed the normal metabolism of the cells.

The suggested formation of dihydroxyacetone from dihydroxy. acetone-phosphate means a loss of potential energy from the cells.
\end{abstract}

Tn the present report the position of a carbon atom in a molecule is indicated Iby a numbering system, which starts at the reactive group, for example an aldehyde or carboxyl group. In this way C-1 of glucose will become C-3 of glyceraldehyde phosphate, and later lactate, during the glycolytic process. In case of glycerol, C-3 is the carbon atom, which will be phosphorylated by glycerokinase, or, if glycerol is oxidized, will become C-3 of L-glyceraldehyde or C-1 of D-glyceraldehyde.

Fermentations of $\left[1^{14} \mathrm{C}\right]$-glucose and $[3,4-14 \mathrm{C}]$-glucose by human and rat polymorphonuclear leukocytes have shown a complicated randomization pattern of the resulting lactate, which might be attributed to the operation of the non-oxidative part of the pentose cycle in addition to a very small complete pentose cycle of $0.1-0.5 \%$ of the catabolized glucose. It was, however, noted, that the fractions of radioactivity appearing in C-1 and C-3 of lactate, when the substrates were $\left[1^{-14} \mathrm{C}\right]$-glucose and $\left[3,4^{-14} \mathrm{C}\right]$-glucose, respectively, were too large to be accounted for by these reactions. It was suggested, therefore, that leukocytes might possess a phosphomonoesterase acting on dihydroxyacetone-phosphate. The resulting dihydroxyacetone,

Acta Chem. Scand. 22 (1968) No. 7 

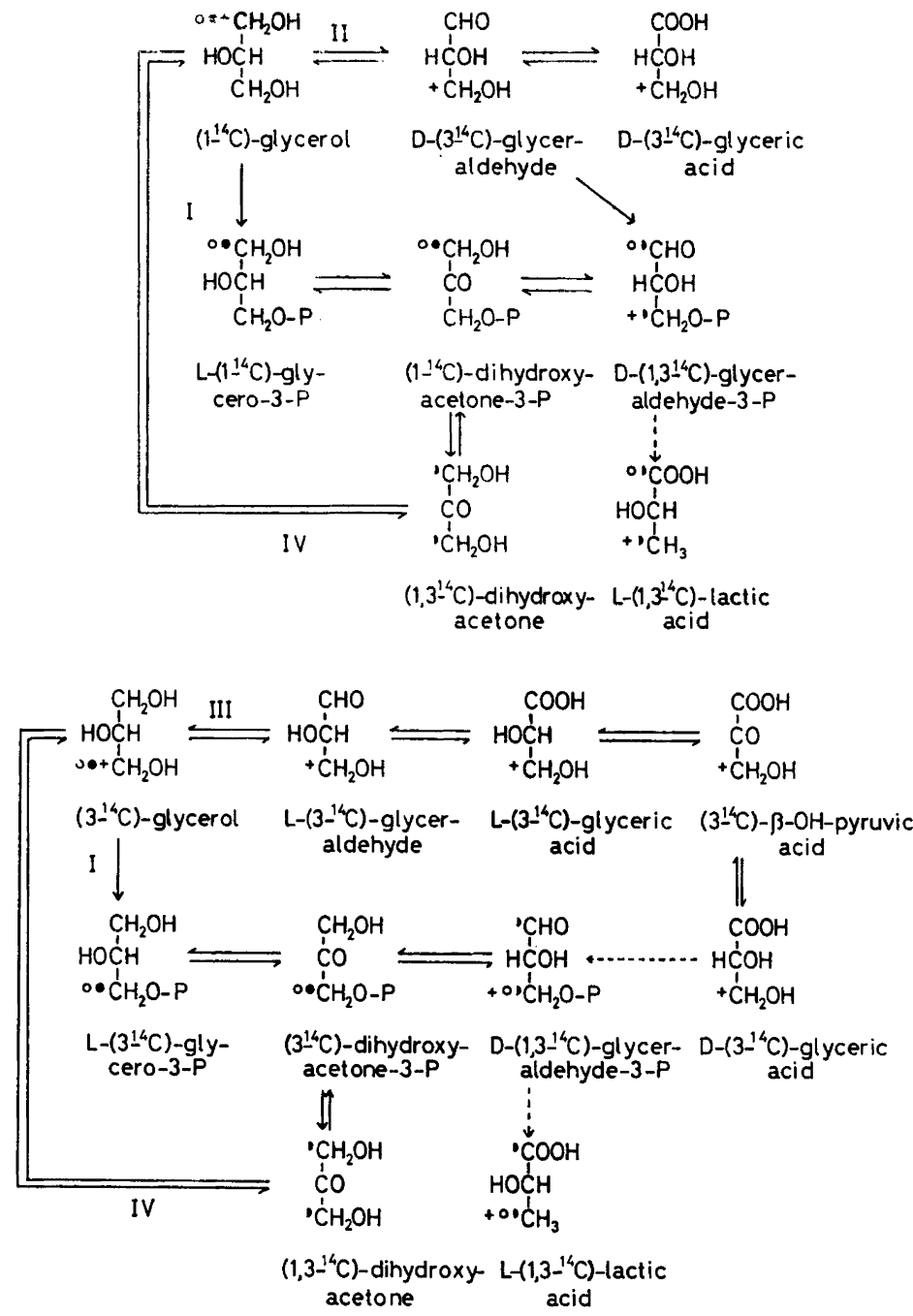

Fig. 1. Theoretical metabolic pathways of glycerol. - The fate of ${ }^{14} \mathrm{C}$ from $\left[1-{ }^{14} \mathrm{C}\right]-$ and $\left[3-{ }^{-14} \mathrm{C}\right]$-glycerol upon phosphorylation and conversion to lactate is followed by open circles (pathway I). The randomization of a ${ }^{14} \mathrm{C}$ labelled carbon atom in dihydroxyacetone is followed by black circles. The fate of a ${ }^{14} \mathrm{C}$ labelled carbon atom, when glycerol is first oxidized to D-glyceraldehyde or L-glyceraldehyde (lower figure) is followed by crosses (pathways II and III). The randomization of this carbon atom in dihydroxyacetone upon isomerization of D-glyceraldehyde-3-phosphate to dihydroxyacetone-3-phosphate is not shown. Dihydroxyacetone is considered formed from dihydroxyacetone-3-phosphate by the action of a phosphatase. Also dihydroxyacetone might be thought formed directly from glycerol by the action of glycerol dehydrogenase (pathway IV). 
which exhibits optical rotational symmetry, would upon further metabolism give rise to lactate labelled evenly in C-1 and C-3. ${ }^{1}$ To elucidate this point incubations have been carried out with ${ }^{14} \mathrm{C}$ labelled glycerol or glyceraldehyde as substrates.

\section{THEORY}

Glycerol possesses two structurally identical primary carbinol groups, which, however, can be differentiated as the compound does not possess optical rotational sym. metry, i.e. the molecular model of glycerol examplified by C-aabd cannot be superimposed on its mirror image with retention of the steric relationship at the secondary carbinol group. ${ }^{2}$ From isotopic experiments as well as from the formation of only one optical isomer, it has been shown, that glycerokinase distinguishes between the primary carbinol groups and therefore is considered to require two-dimensional attachment of the substrate at three sites. Glycerol obtained from $\mathrm{L}-\left[3-{ }^{14} \mathrm{C}\right]$-serine is designated $\left[3-{ }^{14} \mathrm{C}\right]$-glycerol and is phosphorylated at the labelled carbon atom. Glycerol obtained from $\mathrm{D}-\left[3{ }^{14} \mathrm{C}\right]$-serine is designated $\left[1-{ }^{14} \mathrm{C}\right]$-glycerol and is phosphorylated at the unlabelled carbon. ${ }^{3-5}$

The fate of $\left[1^{-14} \mathrm{C}\right]$-glycerol or $\left[3^{-{ }^{14}} \mathrm{C}\right]$-glycerol upon an eventual phosphorylation (pathway I) is illustrated in Fig. 1 (open circles), and it is observed, that the label will appear exclusively at C-1, or C-3, respectively, of the lactate. If a symmetrical compound, such as dihydroxyacetone, occurs during the metabolism of glycerol the label in both $\left[1-{ }^{14} \mathrm{C}\right]$ - and $\left[3-{ }^{14} \mathrm{C}\right]$-glycerol would be randomized to $\mathrm{C}-3$ or $\mathrm{C}-1$, respectively, of lactate (black circles and half-circles). Based on similar considerations the formation of dihydroxyacetone as an intermediate for part of the glucose and glycerol catabolized by propionic acid bacteria has been strongly suggested. ${ }^{6}$

In liver it has been shown, that the initial step in the metabolism of $\mathrm{D}-\left[3-{ }^{14} \mathrm{C}\right]$-glyceraldehyde is a reduction to glycerol. ${ }^{7}$ The reverse reaction, an oxidation of glycerol to D-glyceraldehyde (pathway II) or L-glyceraldehyde (pathway III) must therefore also be considered possible initial steps for glycerol metabolism in leukocytes. The metabolic sequence for L-glyceraldehyde has been adopted from findings in liver..$^{8,9}$ It is noted, that the label (crosses) in [1-14 C]-glycerol upon oxidation appears in position 3 of $\mathrm{D}$ glyceraldehyde and thus in C-3 of lactate, whereas the label in $\left[3 .{ }^{14} \mathrm{C}\right]$-glycerol retains its position in C-3 of lactate from L-glyceraldehyde. Generally, the degree of randomization in lactate from one of the ${ }^{14} \mathrm{C}$-labelled glycerols should depend on the extent of oxidation to either L-glyceraldehyde or D-glyceraldehyde. The relative participation of the two possible oxidative steps is assumed to be constant and mirror image randomization patterns in lactate from $\left[1{ }^{14} \mathrm{C}\right]$ - and $\left[3^{-{ }^{14}} \mathrm{C}\right]$-glycerol should be expected.

The fourth initial reaction of glycerol could theoretically be mediated through the action of glycerol dehydrogenase (E.C.1.1.1.6), which in bacteria is known to form dihydroxyacetone directly. ${ }^{10,11}$ In this case identical randomization patterns should be found in lactate from $\left[1-{ }^{14} \mathrm{C}\right]$ - and $\left[3-{ }^{14} \mathrm{C}\right]$-glycerol.

If one or more of these initial reactions are operating in leukocytes the following conclusions may be reached with respect to the formation of dihydroxyacetone.

1) The presence of both the phosphorylative step and the oxidative steps to glyceraldehyde in the initial metabolism of glycerol would prevent an interpretation of the randomization pattern found in lactate in terms of a formation of dihydroxyacetone, but the labelling pattern in lactate from $\left[1-{ }^{14} \mathrm{C}\right]$-glycerol should be a mirror-image of the pattern obtained with $\left[3{ }^{14} \mathrm{C}\right]$-glycerol. 2) If glycerol solely is phosphorylated, a randomization from C-1 to C-3 or vice versa in lactate would strongly indicate a formation of dihydroxyacetone, and a similar conclusion may be made, if 3 ) glycerol in addition is metabolized to L-glyceraldehyde, where the label is situated in the same position as in L-glycerophosphate. 4) If glycerol solely is metabolized via $\mathrm{D}$ - and L-glyceraldehyde no conclusion on the formation of dihydroxyacetone can be made from the randomization pattern in lactate, but the patterns obtained with $\left[1-{ }^{14} \mathrm{C}\right]$ - and $\left[3-{ }^{14} \mathrm{C}\right]$-glycerol should show mirror image randomizations. It would, however, be possible by using labelled glyceraldehyde as substrates to infer the formation of dihydroxyacetone from the randomization pattern in lactate, provided no shuttle between $\mathrm{I}_{\text {- }}$ and $\mathrm{D}$-glyceraldehyde over glycerol exists. 5) If glycerol is metabolized either to D-glyceraldehyde or L-glyceraldehyde a randomization in lactate would indicate dihydroxyacetone as an intermediate.

Acta Chem. Scand. 22 (1968) No. 7 
A dehydrogenase distinguishing the enantiomers would require three point attachment of the substrate, but it is possible to arrange the molecular model of glycerol in such a way, that both enantiomers might be formed by the same enzyme. One of the enantiomers would, however, appear to be weakly bound because of steric hindrance of the carbon bond $\mathrm{H}$-atom of the secondary carbinol group, if it is assumed, that the enzyme surface is plane. The formation of both enantiomers would therefore appear less likely. 6) Finally, an outcome with identical labelling patterns in lactate from $\left[1-{ }^{14} \mathrm{C}\right] \cdot$ and $\left[3-{ }^{14} \mathrm{C}\right]$-glycerol would suggest the operation of pathway IV.

\section{EXPERIMENTAL}

Polymorphonuclear leukocytes (95 \% pure) were obtained from the peritoneal cavity of male rats of the Holzmann strain as previously described. ${ }^{7}$ The cells were washed and $2-5 \times 10^{8}$ leukocytes were incubated for $30 \mathrm{~min}$ in $10 \mathrm{ml}$ Krebs-Ringer bicarbonate buffer containing $1 \%$ gelatine, $0.2 \%$ sodium acetate, and non-labelled glucose and labelled glycerol or glyceraldehyde as indicated. The atmosphere was $95 \% \mathrm{O}_{2}+5 \%$ $\mathrm{CO}_{2}(\mathrm{pH} 7.4)$.

The incubations were terminated by addition of $1 \mathrm{ml} 3 \mathrm{M} \mathrm{HCl}$ in methanol, and the leukocytes were removed from the incubation mixture by centrifugation. Metabolic acids were separated from the supernatant by $48 \mathrm{~h}$ continuous ether-extraction, and lactic acid and acetic acid were purified on Dowex-1 (formate) and acid Celite columns and subsequently degraded carbon by carbon as described. ${ }^{1}$ All ${ }^{14} \mathrm{C}$ determinations from the degradations were made on ${ }^{14} \mathrm{CO}_{2}$ in a gas proportional counter.

Measurable quantities of glyceric acid were formed and the presence of the compound was verified as follows. The radioactivity eluted from the Dowex-1 (formate) columns with $0.1 \mathrm{M}$ HCOOH separated on subsequent chromatography on acid Celite with butanol/chloroform $(0 \rightarrow 35 \% \mathrm{v} / \mathrm{v})$ in activity corresponding to lactic acid and in radioactivity, which was retained on the columns. The latter was recovered with water and the eluates desalted, lyophilized, and dissolved in a small volume of water. Aliquots were chromatographed on Whatmann No. I paper in methyl-ethyl-ketone:formic acid: acetone:water (160:2.5:9:22 by vol.) and gave $R_{F}$ values of 0.46 and 0.48 corresponding to authentic standards of glyceric acid. The identity was subsequently proved by addition of 2 mmoles cold glyceric acid to an aliquot of the radioactive compound, formation

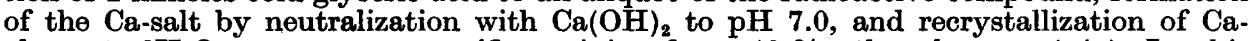
glycerate, $2 \mathrm{H}_{2} \mathrm{O}$ to constant specific activity from $40 \%$ ethanol-water $(\mathrm{v} / \mathrm{v})$. In this way $86 \%$ of the activity originally eluted from the Celite columns with water was accounted for as glyceric acid. The specific activity was 14300 scintillation counts/ $\mathrm{min} / \mathrm{mM}$ on a Tri-Carb No. 3214 (Packard Instr.).

The glyceric acid was degraded by oxidation with $0.5 \mathrm{M} \mathrm{NaIO}_{4}$ in a phosphate buffer ( $\mathrm{pH}$ 5.8).12 $\mathrm{C}-1$ was recovered as $\mathrm{CO}_{2}$ and $\mathrm{C}-3$ as formaldehyde, which was precipitated as formaldimedone, recrystallized, and completely oxidized to $\mathrm{CO}_{2}$. The recovery of radioactivity during the degradation procedure was checked by total oxidation of a sample of glyceric acid.

Materials. $\left[1{ }^{14} \mathrm{C}\right]$ - and $\left[3-{ }^{14} \mathrm{C}\right]$-glycerol were a generous gift from Dr. M. L. Karnowsky. D- $\left[3{ }^{14} \mathrm{C}\right]$ - and L- $\left[3-{ }^{14} \mathrm{C}\right]$-glyceraldehyde were similarly kindly supplied by Dr. B. Landau. $\left[1,3 \cdot{ }^{14} \mathrm{C}\right]$ - glycerol was obtained from Volk Radiochemical Co. and $\left[2{ }^{14} \mathrm{C}\right]$ - glycerol was from Research Specialities Co. The radioactive substrates have previously been degraded and the position of the label(s) ascertained. ${ }^{6}$

\section{RESULTS}

The recovery of radioactivity from labelled glycerol and glyceraldehyde in $\mathrm{CO}_{2}$ and lactate is recorded in Table 1 . It is observed, that the addition of glucose to the incubation mixture appears to stimulate the metabolism of glycerol (expts. 1 and $2 v s$. expts. 3 and 4 ), whereas the incorporation of ${ }^{14} \mathrm{C}$ from glycerol in lactate was much lower in the presence of high concentra- 

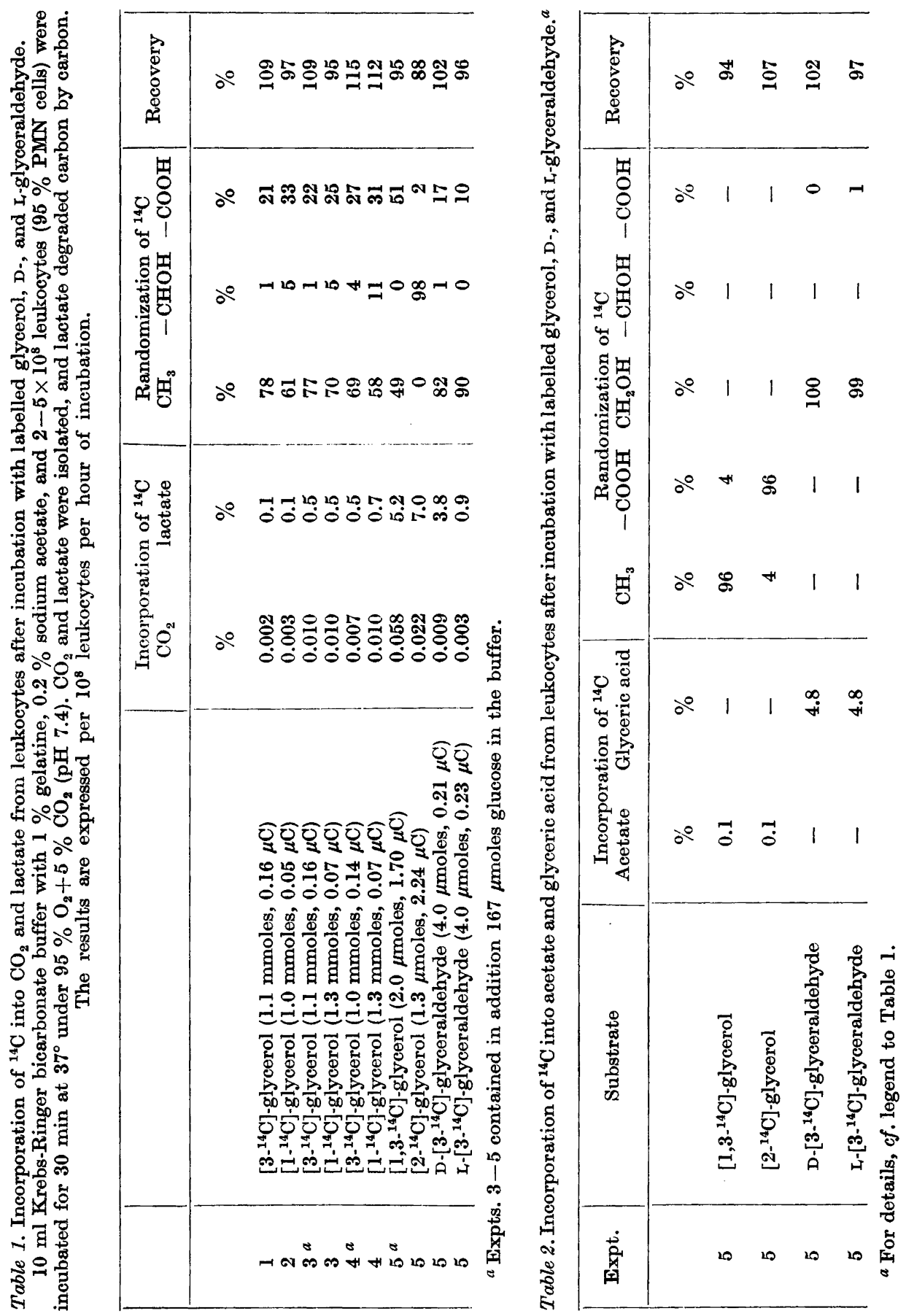

Acta Chem. Scand. 22 (1968) No. 7 
tions of glycerol (expts. $1-4$ vs. expt. 5). ${ }^{14} \mathrm{C}$ of D-glyceraldehyde showed a four times higher incorporation in lactate than $\operatorname{did}{ }^{14} \mathrm{C}$ of $\mathrm{L}_{\mathrm{L}}$-glyceraldehyde.

In the experiments with $[3-14 \mathrm{C}]$-glycerol the degradation of the resulting lactates showed, that $69-78 \%$ of the activity appeared corresponding to the original position and $21-27 \%$ was randomized to $\mathrm{C}-1$. With $\left[1-{ }^{-14} \mathrm{C}\right]$ glycerol, however, only $25-33 \%$ of the activity in lactate corresponded to the original position (C-1), and 58-70\% was found in $\mathrm{C}-3 .{ }^{14} \mathrm{C}$ of $\left[1,3-{ }^{14} \mathrm{C}\right]$ and $\left[2-{ }^{14} \mathrm{C}\right]$-glycerol showed no randomization in lactate. ${ }^{14} \mathrm{C}$ of $\mathrm{D}-\left[3-{ }^{14} \mathrm{C}\right]-$ glyceraldehyde randomized to C-1 of lactate with $17 \%$, whereas a significantly lower randomization was observed, when $\mathrm{I}_{-}-\left[3^{-14} \mathrm{C}\right]$-glyceraldehyde was the substrate.

Detectable amounts of activity in acetate were only observed in experiments with $\left[1,3-{ }^{14} \mathrm{C}\right]$ - and $\left[2-{ }^{14} \mathrm{C}\right]$-glycerol, and the labelling patterns of acetates were consistent with formation of acetate solely by decarboxylation of pyruvate (Table 2). In the experiments with $\mathrm{D}-\left[3^{-14} \mathrm{C}\right]$-glyceraldehyde and $\mathrm{L}_{-}-\left[3^{-14} \mathrm{C}\right]-$ glyceraldehyde appreciable amounts of activity were recovered in glyceric acid. A degradation showed, that no randomization of ${ }^{14} \mathrm{C}$ from the original position of the label had occurred (Table 2).

The extent of ${ }^{14} \mathrm{CO}_{2}$ formation parallelled the incorporation of activity in $\mathrm{C}-1$ of lactate. ${ }^{14} \mathrm{CO}_{2}$ from $\left[3-{ }^{14} \mathrm{C}\right]$-glycerol was higher than previously found ${ }^{1}$ with $\left[6-{ }^{14} \mathrm{C}\right]$-glucose $(0.001 \%)$, which is accounted for by the extensive randomization of ${ }^{14} \mathrm{C}$ to $\mathrm{C}-1$ of lactate.

\section{DISCUSSION}

In experiments $2-4$ lactate was formed from glycerol with a rate of 5-9 $\mu$ moles $/ 10^{8}$ leukocytes $/ \mathrm{h}$, which is comparable to the glucose metabolism of these cells. ${ }^{1,13}$

In leukocytes L- and D-glyceraldehyde were apparently not metabolized via glycerol by specific dehydrogenases, as the resulting lactates had different randomization patterns. In addition glyceric acid accumulated both when $D$ - and $\mathrm{L}_{-}$-glyceraldehyde was the substrate. $\mathrm{D}-\left[{ }^{-14} \mathrm{C}\right]$-Glyceraldehyde might have been partly oxidized and partly reduced and phosphorylated giving rise to the randomization observed in lactate, but a similar event for $\mathrm{L}_{-}-\left[3-{ }^{14} \mathrm{C}\right]-$ glyceraldehyde would not explain the randomization of ${ }^{14} \mathrm{C}$ in lactate from this compound. It appears reasonable to accept, that in leukocytes D-glyceraldehyde primarily is metabolized directly by phosphorylation or by phosphorylation after oxidation to D-glyceric acid, while $\mathrm{L}_{-}$-glyceraldehyde is metabolized to L-glyceric acid and further to D-glyceric acid or D-glyceraldehyde before phosphorylation (Fig. 1).

Glyceric acid from $L_{-}$- or D-glyceraldehyde was not randomized, which excludes that the enantiomorphs are in equilibrium over glycerol. The requirements of condition 4 ( $c f$. theory) appears to have been met for the interpretation of the randomization of ${ }^{14} \mathrm{C}$ in lactate from glyceraldehyde in terms of dihydroxyacetone formation ( $c f$. Fig. 1). The labelling of C-1 of lactate was significantly greater with $\mathrm{D}$-glyceraldehyde than with $\mathrm{L}_{\text {-glyceraldehyde, and }}$ this was parallelled by a greater formation of ${ }^{14} \mathrm{CO}_{2}$. The same proportion of molecules should, however, be randomized in dihydroxyacetone from both 
substrates. An explanation would be, that D-glyceric acid from L-glyceraldehyde is directly phosphorylated instead of being metabolized over $D$ glyceraldehyde-3-phosphate. The resulting phosphoglycerate would be less likely to reach dihydroxyacetone-phosphate than D-glyceraldehyde-3-phosphate.

A randomization from C-3 to $\mathrm{C}-1$ of ${ }^{14} \mathrm{C}$ from glyceraldehyde could also occur if the carbon atoms of glyceraldehyde became susceptible ${ }^{14}$ to the action of the transketolase-transaldolase system, which is active in leukocytes. ${ }^{15,16}$ It would then, however, have been expected, that some ${ }^{14} \mathrm{C}$ was randomized from $\mathrm{C}-3$ to $\mathrm{C}-2,{ }^{17}$ and this was not the case.

The experiments with $\left[1^{14} \mathrm{C}\right]-$ and $\left[3^{-14} \mathrm{C}\right]$-glycerol gave nearly identical labelling patterns of lactate, and the lack of mirror-image randomizations (cf. conditions $\mathbf{1 - 5}$ in theory) necessitates the assumption, that the initial metabolic step in these experiments primarily was an oxidation at C-2 to dihydroxyacetone by glycerodehydrogenase or non-specifically by some normally occurring dehydrogenase. Glycerodehydrogenase has been demonstrated in bacteriae, ${ }^{10,11}$ but so far not in leukocytes.

To explain the randomization pattern in lactate from $\left[1-{ }^{14} \mathrm{C}\right]-$ and $\left[{ }^{-14} \mathrm{C}\right]-$ glycerol it is furthermore necessary to assume, that the dihydroxyacetone, which would be evenly labelled in the carbinol groups, upon further metabolism to lactate, was the object of isotopic dilution. An effective dilution of C-1 could occur at the dihydroxyacetone level, if the transketolase catalyzed decarboxylation of hydroxypyruvate with formaldehyde as acceptor molecule ${ }^{18}$ was reversible with formation of $\mathrm{C}-3$ labelled hydroxypyruvate from $\left[1,3-{ }^{14} \mathrm{C}\right]$ dihydroxyacetone and $\mathrm{CO}_{2}$.

The experiments with $\left[1,3-{ }^{14} \mathrm{C}\right]$ - and $\left[2-{ }^{14} \mathrm{C}\right]$-glycerol differed strikingly from the remaining glycerol experiments as there was a much greater incorporation of ${ }^{14} \mathrm{C}$ in lactate, and no isotopic dilution or involvement of C-2. The differences in behaviour of $\left[1-{ }^{14} \mathrm{C}\right]-$ or $\left[3^{-14} \mathrm{C}\right]$-glycerol and $[1,3-14 \mathrm{C}]-$ or $\left[2^{-14} \mathrm{C}\right]$-glycerol might be related to the different concentration of glycerol used in the experiments. The high concentration of glycerol $(0.1 \mathrm{M})$ in the experiments with $\left[1-{ }^{14} \mathrm{C}\right]$ - and $\left[3-{ }^{14} \mathrm{C}\right]$-glycerol, which was necessitated by the lower specific activity of these compounds, might have changed the normal metabolism of the cells, for example by inhibiting glyceraldehyde dehydrogenase. These experiments have not given meaningful results, and the initial metabolic fate of glycerol in leukocytes has not been sufficiently explained.

The randomization of ${ }^{14} \mathrm{C}$ from $\mathrm{L}_{-}$and $\mathrm{D}-\left[3-{ }^{14} \mathrm{C}\right]$-glyceraldehyde in lactate appeared best explained by the assumption of dihydroxyacetone as an intermediate for part of the metabolized glyceraldehyde. From the extent of the randomization it is seen, that approx. one third of the glyceraldehyde molecules reaching lactate has passed the dihydroxyacetone stage. If dihydroxyacetone, as suggested, is formed by hydrolysis of dihydroxyacetone-phosphate this means a significant waste of energy.

So far no enzymatic proof of the pathways followed by glycerol or glyceraldehyde is available. Experiments in progress, however, have indicated that human leukocytes are able to hydrolyse dihydroxyacetone-phosphate to dihydroxyacetone and inorganic phosphate and metabolize dihydroxyacetone to lactate. 
Acknowledgements. Most of the reported experiments were done in the laboratory of Dr. Rune Stjernholm, Dept. of Biochemistry, Western Reserve University, Cleveland, and the research was supported by Grant AM-6366 of USPHS. The author wishes to thank Dr. Stjernholm for valuable advice and help. The author was supported by grants from the NATO Science Fellowship Programme, Nordisk Insulinfond, NOVO's fond, and Landsforeningen for Sukkersyge.

\section{REFERENCES}

1. Esmann, V. Diabetologia 4 (1968) 188.

2. Hirschmann, H. In Florkin, M. and Stotz, E. H. Comprehensive Biochemistry, Elsevier, Amsterdam 1963, Vol. 12, Chap. VII.

3. Karnowsky, M. L., Hauser, G. H. and Elwyn, D. J. Biol. Chem. 226 (1957) 881.

4. Hirschmann, H. J. Biol. Chem. 235 (1960) 2762.

5. Bublitz, C. and Kennedy, E. P. J. Biol. Chem. 211 (1954) 963.

6. Stjernholm, R. and Wood, H. G. J. Biol. Chem. 235 (1960) 2757.

7. Landau, B. L. and Merlevede, W. J. Biol. Chem. 238 (1963) 861.

8. Holldorf, A., Holldorf, C., Schnider, S. and Holzer, H. Z. Naturforsch. 14b (1959) 229.

9. Dickens, F. and Williamson, D. H. Biochem. J. 72 (1959) 496.

10. Asnis, R. E. and Brodic, A. F. J. Biol. Chem. 203 (1953) 153.

11. Lin, S. C. C. and Magasanik, B. J. Biol. Chem. 235 (1960) 1820.

12. Sakami, W. Handbook of isotopic tracer methods, Western Reserve University, Cleveland 1955, p. 72.

13. Esmann, V. Carbohydrate metabolism and respiration in leukocytes from normal and diabetic subjects, Universitetsforlaget, Aarhus 1962.

14. Esmann, V., Noble, E. P. and Stjernholm, R. Acta Chem. Scand. 19 (1965) 1672.

15. Stjernholm, R. and Noble, E. P. J. Biol. Chem. 236 (1961) 614.

16. Stjernholm, R. and Noble, E. P. Arch. Biochem. 100 (1963) 200.

17. Katz, J. and Rognstad, R. Biochemistry 6 (1967) 2227.

18. Dickens, F. and Williamsen, D. H. Nature 181 (1958) 1790.

Received February 22, 1968. 